\title{
Predicting milk protein responses and the requirement of metabolizable protein by lactating dairy cows
}

\author{
L. E. Moraes, ${ }^{*} \dagger^{1}$ E. Kebreab, ${ }^{*}$ J. L. Firkins, $\dagger$ R. R. White, $\ddagger$ R. Martineau, $\S$ and H. Lapierre§ \\ *Department of Animal Science, University of California, Davis 95616 \\ †Department of Animal Sciences, The Ohio State University, Columbus 43210 \\ †Department of Animal and Poultry Sciences, Virginia Tech, Blacksburg 24061 \\ §Agriculture and Agri-Food Canada, Sherbrooke, Quebec, Canada J1M 0C8
}

\begin{abstract}
The objective of this study was to develop a modeling framework to predict milk protein yield responses to varying metabolizable protein (MP) supplies and to determine the requirement of MP by lactating dairy cows. The logistic curve was used to model milk protein yield while accounting for a variable efficiency of MP utilization and between-study variability. Models were developed with databases from 2 recently published meta-analyses and based on either total MP supply or MP supply available for milk production. All models provided reasonable fit to data, with root mean square prediction error ranging from 18 to $20 \%$ of the average milk protein yield. The estimated horizontal asymptotes were 1.17 (posterior $\mathrm{SD}=0.02$ ) and 1.55 (posterior $\mathrm{SD}$ $=0.06$ ) in the 2 databases, suggesting that the limiting milk protein yield, as MP supply increases, converges to 1.17 or $1.55 \mathrm{~kg} / \mathrm{d}$ in the environments determined by the 2 databases. The observed efficiencies ranged from 0.75 to 0.18 when total MP supply was used as the denominator and above 1 to 0.24 when the MP supply available for milk production was used as the denominator. The predicted efficiencies were in good agreement with the data, decreasing nonlinearly with the MP supply. The MP requirement was calculated with a function constructed with the inverse of the logistic model and modified at regions of maximum marginal efficiency and minimum second derivative. This strategy assumes that the MP solution, or the MP needed to predict a given protein yield in the fitted logistic curve, determines the MP requirement for maintenance and lactation. Requirements calculated with the independent variable as total MP supply refer to the total requirement of maintenance plus lactation, whereas the requirement from models based on MP supply available for milk production are referent to the MP required
\end{abstract}

Received December 22, 2016.

Accepted September 22, 2017.

${ }^{1}$ Corresponding author: ferrazdiasdemoraes.1@osu.edu only for lactation. The requirements were, on average, slightly smaller than the ones predicted by the current Northern American feeding system for dairy cows at lower protein yields and greater than currently recommended at high yields.

Key words: protein, requirement, efficiency, metaanalysis

\section{INTRODUCTION}

The dairy industry faces increasing governmental and societal pressure to deliver dairy products at competitive prices while maintaining rigorous environmental stewardship. The number of worldwide policies regulating environmental impacts from livestock operations has increased substantially in the past 2 decades (Oenema, 2004). In the United States, most livestock operations are required to implement nutrient management plans and comply with guidelines, many times updated annually (USDA-EPA, 1999). Nitrogen balance in dairy operations is of particular interest because dietary $\mathrm{N}$ supplied in excess is excreted in manure. Nitrate leaching from manure might contribute to eutrophication of water sources and ammonia volatilization is related to health issues in animals and humans (McCubbin et al., 2002). From a producer's perspective, N not retained in milk or tissue represents an inefficiency on the use of an expensive dietary nutrient. Therefore, augmenting the efficiency of incorporating dietary $\mathrm{N}$ into milk not only increases the economic competitiveness of the dairy industry but also reduces the environmental impact of milk production. A large variation exists on the efficiency of incorporating dietary $\mathrm{N}$ into milk across production systems: Huhtanen and Hristov (2009) reported minimal and maximal efficiency at 14 and $45 \%$, respectively, from 1,734 treatment means from the literature. Dijkstra et al. (2013) estimated a maximum theoretical efficiency around $43 \%$; however, commercial dairies are often far from this maximum theoretical efficiency of $\mathrm{N}$ utilization. To achieve gains in efficiency, a more comprehensive description of nutrient availabil- 
ity from feeds and a more precise determination of the animal's nutrient requirements for various physiological functions are necessary.

A more comprehensive and precise determination of $\mathrm{MP}$ and AA requirements is necessary for matching the delivery with the requirement for various physiological functions of a lactating cow. For instance, the NRC (2001) often underestimates MP allowable milk at low MP supplies and overestimates at greater supplies (Lapierre et al., 2007). This is due to the assumption of a constant efficiency (0.67) of utilization of MP for both maintenance and lactation. The direct implication of the fixed efficiency is that $1.5 \mathrm{~kg}$ of MP is required for each kilogram of true protein outputted in milk, regardless of the level of MP supply. The use of a constant efficiency of utilization of MP for lactation has been challenged by a series of studies (Doepel et al., 2004; Van Duinkerken et al., 2011; Daniel et al., 2016). Furthermore, Metcalf et al. (2008) suggested that the efficiency of utilizing supplied MP for milk true protein synthesis decreased from 0.77 to 0.50 when MP supply varied from $25 \%$ below to $25 \%$ above the predicted MP requirement. The authors suggested that the efficiencies might follow a continuous curvilinear function with respect to the supply. Likewise, Arriola Apelo et al. (2014) suggested that the efficiency of using MP for milk true protein yield decreases with increasing MP supply, possibly in a curvilinear fashion. Daniel et al. (2016) reported cumulative efficiencies of utilizing MP above maintenance decreasing from 0.82 to 0.58 with MP supplies increasing from -0.4 to $+0.3 \mathrm{~kg} / \mathrm{d}$ relative to the MP supply needed for an efficiency of 0.67 .

In this context, the objective of this study was to develop a modeling framework that (1) predicts the milk protein yield response to the increased MP supply and (2) provides a framework for computing the MP requirement while accounting for a variable efficiency of MP utilization. Because of the increasing interest in moving from a MP system to an individual AA system (Arriola Apelo et al., 2014; Lapierre et al., 2014), the framework was structured to be flexible and easily extended to the estimation of efficiencies and requirements of individual AA.

\section{MATERIALS AND METHODS}

\section{Data}

Two distinct but complementary databases from 2 recently published meta-analyses were used in this study. The first database is from a meta-analysis conducted with studies that infused casein postruminally (Martineau et al., 2017). The second database is from a meta-analysis conducted with studies reporting duodenal or omasal N flow (White et al., 2016). In the first database, all studies systematically vary MP supply through casein infusions, providing a controlled system for which variation of protein supply is measured and probably the main factor limiting and driving changes in milk protein yield. The second database encompasses studies with a much broader range of experimental treatments. Not only protein supply but other dietary factors might be limiting and driving milk protein yield. The idea of using these 2 distinct databases is to examine the appropriateness of the framework with 2 different systems and examine a potential need for developing more complex models that account for other factors affecting MP use efficiency, such as energy and AA supplies and potential of cows. By design, studies with casein infusion should have improved AA profile, whereas in the second database studies comprise a varied mix of AA profiles in RUP. For both databases, all studies had at least 2 different MP supplies (i.e., at least 2 treatment means).

\section{Database 1}

The first database was composed of 130 treatment means summarized in 36 scientific publications. The data represents a subset of the data from Martineau et al. (2017). The study from Larsen et al. (2014) was removed from the database because cows were in early transition period (i.e., DIM 4, 15, 29) and likely relying heavily on body reserves to support milk protein yield. Studies for which the standard error of milk protein was not available or could not be approximated through error propagation techniques were also removed from the database. A complete list with all studies used in our analysis is provided as Supplemental Data (https:// doi.org/10.3168/jds.2016-12507). The meta-design is presented in Figure 1 (panels a and b), and summary statistics of the database are presented in Table 1. In short, the data are composed of studies that infused casein postruminally in lactating dairy cows, systematically altering the MP supply and milk protein yield. For a comprehensive description of the literature search and study selection, see Martineau et al. (2017). When BW was not available, it was assumed to be, respectively, 602 and $564 \mathrm{~kg}$ for North American cows and cows from Europe and other countries (for $25 \%$ of the data), as adopted in the meta-analyses of Martineau et al. (2017) and reported by Huhtanen and Hristov (2009). The total MP supply and MP supply available for milk production were calculated according to Lapierre et al. (2014). Specifically, the total MP supply was determined as the calculated MP supply (NRC, 2001) 
minus the MP supply from endogenous sources entering the duodenum, also calculated according to the NRC (2001). The MP supply available for milk production was calculated as the total MP supply minus the MP required for scurf, urinary endogenous protein, and metabolic fecal protein assuming an efficiency of 0.67 for each component. Scurf protein output was set at $0.2 \mathrm{~g}$ of $\mathrm{CP} / \mathrm{kg}$ of $\mathrm{BW}^{0.6}$ (Swanson, 1977) and urinary endogenous protein output at $2.75 \mathrm{~g}$ of $\mathrm{CP} / \mathrm{kg}$ of $\mathrm{BW}^{0.5}$ (Swanson, 1977) as suggested by the NRC (2001). The metabolic fecal protein was estimated at $15.8 \mathrm{~g}$ of $\mathrm{CP} /$ $\mathrm{kg}$ of DMI, with an average proportion of true protein/ CP of 0.80 (Lapierre et al., 2014). Therefore, both the total MP supply and the MP supply available for milk do not contain the endogenous duodenal flow of protein (Lapierre et al., 2014). Milk true protein yield was used as milk protein output; when not reported, it was assumed to be milk yield times milk protein percentage. If means were reported on a $\mathrm{CP}$ basis, the milk true protein was assumed to be 0.955 times milk CP (for $54 \%$ of the data). When needed, standard errors were approximated as described in Roman-Garcia et al. (2016).

\section{Database 2}

The second database was composed of 356 treatment means summarized in 106 scientific publications. The database is a subset of the data used in the metaanalyses by Roman-Garcia et al. (2016) and White et al. (2016). Studies for which the standard error of milk protein yield was not available or could not be approximated through error propagation techniques were removed from the database. The complete list of all studies used in the analysis is provided as Supplemental Data (https://doi.org/10.3168/jds.2016-12507). The meta-design is presented in Figure 1 (panels c and d), and summary statistics of the data are presented in
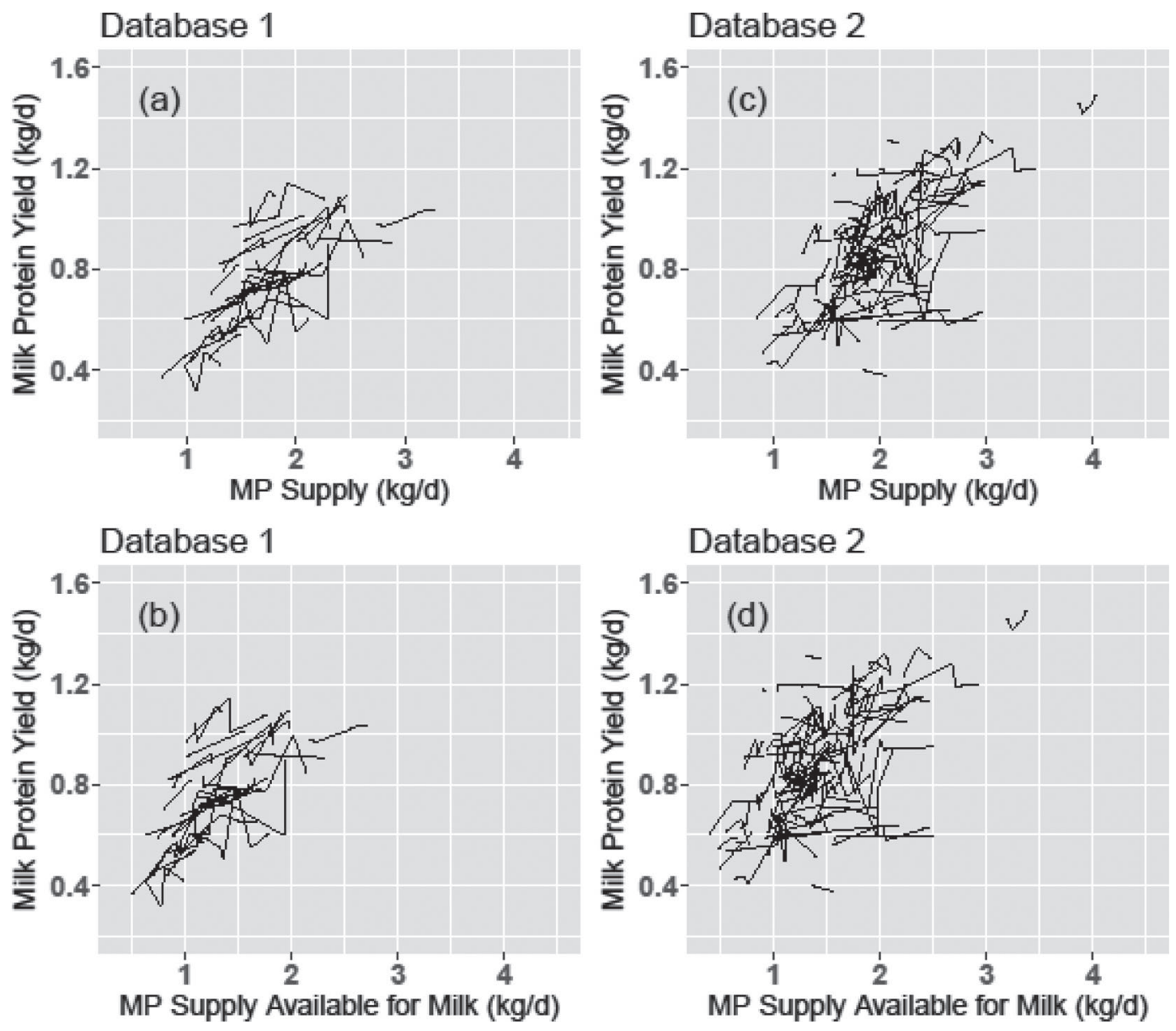

Figure 1. Meta-design showing the relationship between milk protein yield and total MP supply or MP supply available for milk production (MP supply minus MP required for maintenance). Panels (a) and (b) use data from Martineau et al. (2017), and panels (c) and (d) use data from White et al. (2016). Treatment means from the same publication are connected with straight lines. 
Table 1. Summary statistics of the 2 databases used for fitting the logistic models

\begin{tabular}{|c|c|c|c|c|}
\hline Variable & Mean & Minimum & Maximum & $\mathrm{SD}$ \\
\hline \multicolumn{5}{|c|}{ Database 1 (from Martineau et al., 2017) } \\
\hline MP supply ${ }^{1}(\mathrm{~kg} / \mathrm{d})$ & 1.71 & 0.778 & 3.266 & 0.47 \\
\hline MP supply for milk ${ }^{2}(\mathrm{~kg} / \mathrm{d})$ & 1.29 & 0.506 & 2.69 & 0.42 \\
\hline Milk protein yield ${ }^{3}(\mathrm{~kg} / \mathrm{d})$ & 0.729 & 0.319 & 1.14 & 0.19 \\
\hline $\mathrm{BW}^{4}(\mathrm{~kg})$ & 564 & 466 & 714 & 51.4 \\
\hline DMI $(\mathrm{kg} / \mathrm{d})$ & 16.4 & 9.08 & 24.8 & 3.30 \\
\hline Milk yield (kg/d) & 23.6 & 10.7 & 40.0 & 6.79 \\
\hline Milk protein (\%) & 3.25 & 2.66 & 4.14 & 0.27 \\
\hline Milk fat $(\%)$ & 4.01 & 2.58 & 5.40 & 0.64 \\
\hline Diet NDF (\% of DM) & 38.1 & 20.6 & 57.1 & 6.89 \\
\hline Diet CP $(\%$ of $\mathrm{DM})$ & 15.5 & 11.0 & 23.35 & 1.93 \\
\hline Diet $\mathrm{NE}_{\mathrm{L}}(\mathrm{Mcal} / \mathrm{kg}$ of $\mathrm{DM})$ & 1.56 & 1.26 & 1.88 & 0.10 \\
\hline DIM & 123 & 20 & 321 & 62 \\
\hline \multicolumn{5}{|c|}{ Database 2 (from White et al., 2016) } \\
\hline MP supply ${ }^{5}(\mathrm{~kg} / \mathrm{d})$ & 2.02 & 0.849 & 4.03 & 0.501 \\
\hline MP supply for milk ${ }^{6}(\mathrm{~kg} / \mathrm{d})$ & 1.45 & 0.404 & 3.37 & 0.480 \\
\hline Milk protein yield ${ }^{3}(\mathrm{~kg} / \mathrm{d})$ & 0.891 & 0.376 & 1.49 & 0.216 \\
\hline BW $(\mathrm{kg})$ & 599 & 480 & 788 & 55.7 \\
\hline DMI (kg/d) & 20.3 & 9.12 & 30.4 & 3.47 \\
\hline Milk yield (kg/d) & 28.9 & 10.2 & 44.7 & 7.44 \\
\hline Milk protein (\%) & 3.15 & 2.63 & 3.74 & 0.228 \\
\hline Milk fat (\%) & 3.59 & 2.11 & 5.05 & 0.461 \\
\hline Diet NDF (\% of DM) & 32.9 & 22.0 & 50.9 & 5.81 \\
\hline Diet $\mathrm{CP}(\%$ of $\mathrm{DM})$ & 17.3 & 10.3 & 24.6 & 2.17 \\
\hline Diet $\mathrm{NE}_{\mathrm{L}}(\mathrm{Mcal} / \mathrm{kg}$ of $\mathrm{DM})$ & 1.66 & 1.37 & 1.90 & 0.09 \\
\hline DIM & 104 & 16 & 323 & 55 \\
\hline
\end{tabular}

${ }^{1}$ NRC (2001) MP supply (diet plus casein infusion) minus the MP supply from duodenal endogenous flow, also calculated with the NRC (2001), as suggested by Lapierre et al. (2014).

${ }^{2} \mathrm{MP}$ supply, as above, minus the MP supply required for scurf, and endogenous urinary and metabolic fecal protein; see text for details.

${ }^{3}$ If not available (for $54 \%$ of the database 1 and for $17 \%$ of database 2), assumed to be 0.955 times CP.

${ }^{4} \mathrm{BW}$ was not reported in all publications (not available for $25 \%$ of the data). When not available, it was assumed to be, respectively, 602 and $564 \mathrm{~kg}$ for North American cows and cows from Europe and other countries.

${ }^{5}$ According to White et al. (2017a,b); again, it does not contain duodenal endogenous flow.

${ }^{6} \mathrm{MP}$ supply minus MP required for scurf, endogenous urinary and metabolic fecal protein as described in item 1.

Table 1. For a comprehensive description of the criteria for literature search, study inclusion, and all calculations, see Roman-Garcia et al. (2016) and White et al. (2016). In short, the database represents a much larger set of experimental conditions with studies that measured duodenal or omasal $\mathrm{N}$ flow in lactating dairy cows. This database is notably different than database 1 in the sense that not all studies focused exclusively on investigating changes in protein supply with a highly controlled setting such as casein infusions. A much larger diversity of experimental treatments is available in this database, introducing more variation in the relationship between dependent and independent variables but more likely representing the variation observed in practical situations. For all studies, the MP supply was calculated with observed microbial flows and RUP according to White et al. (2017a,b). Studies for which inputs needed for calculation of MP were not reported were excluded from the database. Similarly to database 1, the MP supply does not contain the supply from endogenous sources entering the duodenum. A comprehensive description of MP calculations, as well as a detailed comparison with NRC (2001) MP supplies are available in these 2 publications. The MP supply available for milk production was calculated as the MP supply minus the MP supply required for maintenance (scurf, urinary endogenous, and metabolic fecal protein, with all fractions computed as in NRC, 2001). Milk true protein yield was used as milk protein output; when not reported, it was assumed to be milk yield times milk protein percentage. If means were reported on a CP basis, the milk true protein was assumed to be 0.955 times milk CP ( $17 \%$ of the data). When needed, standard errors were approximated as described in Roman-Garcia et al. (2016).

\section{Modeling Framework}

The general strategy was to fit a nonlinear hierarchical model to represent the relationship between milk 
protein yield and MP supply. The nonlinear model directly represented a variable efficiency of MP utilization for milk protein yield and accounted for the between-study differences in all parameters of the logistic curve. The sparsity of the data within each experiment in each publication created a challenge for fitting a nonlinear mixed model with experimentspecific parameters because most experiments had only 2 to 3 treatment means. Therefore, 2 strategies were used in model fitting. The first strategy was to assume that the clustering of the data for the meta-analysis was within publication and not within each experiment in each publication. The implication of this assumption is that the model will estimate publication-specific parameters rather parameters specific to experiment within publication. With this assumption, there are more records within each cluster, increasing the range of measurements in the $x$-axis variable for each cluster. The consequence of this assumption is that all records from the same publication will be described by the same set of random deviations from the mean population parameters, regardless of the experiment, within that publication, from which the record originated.

The second strategy was to use a model fitting strategy with 2 steps. First, pooled estimates (across publications) of model parameters were obtained using generalized nonlinear least squares. The reason for using generalized least squares is that treatment means often have different precision due to, for example, distinct experimental design and number of experimental units. Therefore, the error's variance was weighted by the standard error of the treatment means in the original publications. Standard errors were truncated at half of the mean (Roman-Garcia et al., 2016) and were divided by their mean, shifting the mean of the weights to 1 (St-Pierre, 2001; Roman-Garcia et al., 2016). In the second step, Bayesian hierarchical models were fitted to both databases using the pooled estimates, from each database, as hyperparameters of the prior distribution of the logistic mean population parameters. Bayesian hierarchical models are particularly suited for metaanalysis. These models allow each study to have its own set of parameters. These study-specific parameters follow a distribution for which the mean vector is the set of parameters common to all studies. In the frequentist sense, the mean population parameters can be seen as representation of fixed effects, and the random deviations for each study as the random effects that "enter the model" nonlinearly. Three nonlinear models were initially used to represent the relationship between milk protein yield and MP supply: logistic, Gompertz, and monomolecular (Thornley and France, 2005). The logistic curve most often provided the smallest Akaike information criteria and was, therefore, chosen for further model development.

\section{Model}

The model was specified in 3 hierarchies for which the first hierarchy specifies a model for the data given the model parameters and variance:

$$
y_{i j} \mid \boldsymbol{\theta}_{i}, \sigma^{2} \sim N\left[f\left(x_{i j}, \boldsymbol{\theta}_{i}\right), w_{i j} \sigma^{2}\right]
$$

where $y_{i j}$ is the $j$ th milk protein yield $\left(j=1, \ldots, n_{i}\right)$ in the $i$ th publication $(i=1, \ldots, m), x_{i j}$ is the corresponding MP supply, $\boldsymbol{\theta}_{i}=\left(\theta_{1, i} \theta_{2, i} \theta_{3, i}\right)^{\mathrm{T}}$ is the vector of parameters specific to the ith publication, and $w_{i j}$ are the weights (computed from the standard errors of the treatment means) used to weight the variance $\sigma^{2}$. The logistic curve was parameterized as follows:

$$
f\left(x_{i j}, \boldsymbol{\theta}_{i}\right)=\frac{\theta_{1, i}}{1+\theta_{2, i} \exp \left(-x_{i j} / \theta_{3, i}\right)},
$$

where $\theta_{1, i}$ is the asymptote, and $\theta_{2, i}$ and $\theta_{3, i}$ the parameters associated with the amplitude and steepness of the curve. The second hierarchy specifies a model for the between-publication variability. To improve computational efficiency and numerical stability, the model was parameterized in terms of the Cholesky factors (Stan Development Team, 2016a). Specifically, $\boldsymbol{\theta}_{i}$ $=\boldsymbol{\beta}+\mathbf{D L b}_{i}$ where $\boldsymbol{\beta}$ is the vector of mean population parameters, $\mathbf{D}$ is a diagonal matrix with the coefficient scales, $\mathbf{L}$ is a lower triangular matrix with the Cholesky factors of the correlation matrix, and $\mathbf{b}_{i}$ is a vector following a normal distribution centered at zero:

$$
\begin{gathered}
\boldsymbol{\theta}_{i}=\boldsymbol{\beta}+\quad \mathbf{D} \\
{\left[\begin{array}{l}
\theta_{1, i} \\
\theta_{2, i} \\
\theta_{3, i}
\end{array}\right]=\left[\begin{array}{l}
\beta_{1} \\
\beta_{2} \\
\beta_{3}
\end{array}\right]+\left[\begin{array}{lllc}
\tau_{1} & & \\
& \tau_{2} & \\
& & \tau_{3}
\end{array}\right]\left[\begin{array}{llc}
l_{11} & & \\
l_{21} & l_{23} & \\
l_{31} & l_{32} & l_{33}
\end{array}\right]\left[\begin{array}{l}
b_{1, i} \\
b_{2, i} \\
b_{3, i}
\end{array}\right] .}
\end{gathered}
$$

To fully characterize the second hierarchy, it is assumed that

$$
\mathbf{b}_{i} \sim N\left(\mathbf{0}_{3}, \mathbf{I}_{3}\right)
$$

where $\mathbf{0}_{3}$ is a $3 \times 1$ vector of zeros and $\mathbf{I}_{3}$ is the identity matrix of order 3 . The third hierarchy specifies prior distributions for the model parameters: 


$$
\left\{\begin{array}{l}
\boldsymbol{\beta} \sim N\left(\boldsymbol{\beta}_{\text {pooled }}, \boldsymbol{\Gamma}_{\text {pooled }}\right) \\
\tau_{1}, \tau_{2}, \tau_{3}, \sigma \sim \text { half-Cauchy }(0,2.5), \\
\mathbf{L} \sim \operatorname{Lkj} \operatorname{Cholesky}(2)
\end{array}\right.
$$

where $\boldsymbol{\beta}_{\text {pooled }}$ is the vector of pooled estimates (across publications) obtained with generalized nonlinear least squares and $\boldsymbol{\Gamma}_{\text {pooled }}$ is the associated estimated variance-covariance matrix. Further, $\tau_{1}, \tau_{2}, \tau_{3}$, and $\sigma$ were assigned half-Cauchy priors with a small scale (i.e., 2.5) setting weakly informative priors (Stan Development Team, 2016a). The Cholesky factors of the correlation matrix were assigned weakly informative prior using a LkjCholesky distribution with shape parameter equal to 2 (Stan Development Team, 2016a). Briefly, this distribution is a parameterization of the LKJ correlation matrix density (Lewandowski et al., 2009) in terms of its Cholesky factors (Stan Development Team, 2016a). When the shape parameter is equal 1, the LKJ density is uniform over correlation matrices of that order. Increasing the shape parameter, a sharper peak in the density is obtained at the identity matrix.

Pooled estimates were obtained using generalized nonlinear least squares with the nlme $\mathrm{R}$ package (Pinheiro et al., 2016). The Bayesian hierarchical models were fitted in Stan using the Hamiltonian Monte Carlo No-U-Turn Sampler (Carpenter et al., 2016) through the rstan R package (Stan Development Team, 2016b). Two chains with over-dispersed initial values were specified for each parameter; chain mixing, auto-correlation, posterior densities, and the Gelman-Rubin diagnostics (Gelman and Rubin, 1992) were used to visually assess chain convergence and determine the required burn-in period. The fitted models were evaluated with a 5 -fold cross-validation. The data were divided into 5 folds of similar size by randomly allocating publications to each fold. Five training sets were created by leaving each one of the folds out. The testing sets were the folds that were left out of each of the 5 training sets. All treatment means from the same publication were allocated to the same fold so any testing set does not contain treatment means from a publication that was used in the corresponding training set. The predictive ability of the models was then evaluated with the mean square prediction error (MSPE):

$$
\operatorname{MSPE}_{k}=n_{k}^{-1}\left\|\mathbf{y}_{k}-f\left(\mathbf{x}_{k}, \hat{\boldsymbol{\beta}}_{-k}\right)\right\|^{2}
$$

where $n_{k}$ is the number of observations in the $k$ th fold $(k=1, \ldots, 5), \mathbf{y}_{k}$ is the vector of milk protein yields in the $k$ th fold, $f$ is the logistic curve, $\boldsymbol{x}_{k}$ is the correspond- ing vector of MP supplies, $\hat{\boldsymbol{\beta}}_{-k}$ is the vector of posterior means of the mean population parameters estimated with the training set that did not contain observations from the $k$ th fold and $\|$.$\| is the Euclidean norm of a$ vector (i.e., $\|\mathbf{a}\|=\sqrt{a_{1}^{2}+\cdots+a_{n}^{2}}$ ). It is important to point out that in the cross-validation, the hyperparameters for the population mean parameters obtained with generalized nonlinear least squares were also estimated without data from the $k$ th fold.

\section{Efficiency and MP Requirement}

The cumulative efficiency was defined as the ratio of the milk protein yield and the total MP supply or the MP supply available for milk production (i.e., $\delta=$ $y(x)$. When the total MP supply is used as the denominator, the efficiency will, by definition, be lower as it refers to the use of MP to support lactation with the maintenance being assigned to the inefficiency. That is, the denominator of the ratio has the total MP supply that will be used for both milk production and maintenance but the numerator has only the protein export in milk. Conversely, when using the MP available for milk production (with the MP required for maintenance subtracted from the denominator), the efficiency will, by definition, be larger because the maintenance components are no longer part of the inefficiency (i.e., they have been subtracted from the denominator). The determination of the MP requirement using the nonlinear models follows exactly the same logic. Requirements determined with models fitted with MP supply as the independent variable include the requirement for both lactation and maintenance. On the other hand, requirements determined with models that use MP supply available for milk production refer only to the MP required for milk protein secretion.

The requirement of MP, for a given level of milk protein yield, was defined as the MP needed to predict that given milk protein yield in the fitted model, that is, the MP solution. The total MP supply or MP supply available for milk required to predict a given milk protein yield can be determined by inverting the nonlinear model (i.e., solving the model in terms of $x$ ). In this setting, the MP requirement is computed with the inverted curve to determine the level of $x$ needed to predict the given $y$ with the fitted logistic curve. The inverse equation has properties directly determined by the logistic model. For instance, the logistic curve has a horizontal asymptote; that is, the curve converges to a limiting value when MP supply approaches infinity. The curve also determines an intercept $\left[\theta_{1} /\left(1+\theta_{2}\right)\right]$ representing the amount of milk protein outputted with zero MP supply. The requirements by inversion at these 
2 points are biologically senseless. Moreover, not only at the intercept and asymptote but also at neighboring milk protein yields, the computed MP requirement will be excessively small or large. Biologically, at both extremes of the response curve, requirements might be more affected by BW and protein balance changes. For example, if MP supply is deficient with respect to the requirement, cows might use more $\mathrm{N}$ from mobilized tissue. To circumvent these issues and construct a requirement function that is biologically and mathematically sound, we propose to modify the function using properties of the logistic model. The logistic curve has sigmoidal returns with respect to the MP supply. The curve first derivative increases nonlinearly up to the inflection point $\left(\theta_{1} / 2\right)$ at which it achieves its maximum and starts its nonlinear decrease. Doepel et al. (2004) identified a critical MP supply at which the curve second derivative achieves its minimum. Supplies beyond this point are associated with a marginal efficiency that quickly approaches zero. The requirements of MP past this point and approaching the asymptote will be therefore excessively large. The requirement by inversion of the logistic curve at milk protein yields close to the intercept will also be problematic because, by definition, the intercept determines a milk protein yield with zero MP supply. In this context, we propose the following requirement function:

$$
R(y)=I_{\left\{y \leq y_{p}\right\}} \frac{y}{\delta_{p}}+I_{\left\{y_{p}<y<y_{u}\right\}} f(y)^{-1}+I_{\left\{y \geq y_{u}\right\}} \frac{y}{\delta_{u}}
$$

where $R(y)$ is the requirement function determining MP solution for a given level of milk protein yield $y$; $I_{\{B\}}$ is the indicator function that returns 1 if condition $B$ is satisfied and 0 otherwise; $f(y)^{-1}$ is the inverse of the logistic function; $y_{p}$ and $y_{u}$ are the predicted milk protein yields at the inflection point and critical supply, respectively (i.e., $y_{u}$ is the $y$-value at which the second derivative attains its minimum); and $\delta_{p}$ and $\delta_{u}$ are the cumulative efficiencies at the inflection point and the critical MP supply, respectively. For $y<\theta_{1}$ :

$$
f^{-1}(y)=-\theta_{3} \log \left[\frac{1}{\theta_{2}}\left(\frac{\theta_{1}}{y}-1\right)\right],
$$

here and elsewhere in the manuscript $\log (\cdot)$ represents the natural logarithm. The MP supply at the inflection point $\left(x_{p}\right)$ and point of minimum second derivative are $\left(x_{u}\right)$ :

$$
x_{p}=-\theta_{3} \log \left(1 / \theta_{2}\right) \quad \text { and } \quad x_{u}=\theta_{3} \log \left(\sqrt{3 \theta_{2}}+2 \theta_{2}\right) \text {, }
$$

as described by Doepel et al. (2004). The efficiencies in [7] are then defined by

$$
\delta_{p}=f\left(x_{p}\right) / x_{p} \quad \text { and } \quad \delta_{u}=f\left(x_{u}\right) / x_{u} .
$$

Consequently, the requirement function is constructed with 3 distinct but connected parts: if the milk protein yield is lower or equal to the logistic curve inflection point, the MP requirement is given by the milk protein yield divided by the cumulative efficiency at the inflection point. If the milk protein yield is larger or equal to the milk protein yield predicted by the logistic function at the critical MP supply, the requirement is given by the milk protein yield divided by the cumulative efficiency at the critical MP supply. If the milk protein yield is between the inflection point and the milk yield at the critical MP supply, the requirement is given by the inverse of the logistic curve.

\section{RESULTS AND DISCUSSION}

\section{Fitted Models}

The initial analysis of the data explored different nonlinear models for representing the relationship between milk protein yield and MP supply. In particular, we used database 1 as a more controlled system to select a functional form representing the relationship between milk protein output and MP supply. The logistic, Gompertz, and monomolecular models were fitted to data and the logistic model was the one that had the smallest Akaike information criterion. This choice of model is in agreement with Doepel et al. (2004) who chose the logistic model to represent milk protein synthesis as a function of AA supply.

The pooled estimates (across publications) for the 4 models (2 databases, total MP supply, or MP supply available for milk production) are in Table 2. These estimates were used as hyperparameters for fitting the Bayesian hierarchical models that incorporate betweenpublication variability in model parameters (Table $3)$. The fitted curves versus the MP supplies for all models are presented in Figure 2. The fits suggest that models represent the data well. For database 1, the RMSPE (the square root of the MSPE) computed through cross-validation were 19.1 and $20.1 \%$ of the observed milk protein yield when using the MP supply and the MP supply available for milk production, respectively. Likewise, for database 2, the RMSPE was 18.5 and $19.9 \%$ of the mean when using MP supply and MP supply available for milk production, respectively. Therefore, the MSPE suggests reasonable ability of the fitted models in predicting milk protein yield responses 
Table 2. Parameters estimates and SE for the models describing the relationship between milk protein yield and MP supply (all expressed in $\mathrm{kg} / \mathrm{d})^{1}$

\begin{tabular}{lcc}
\hline Model $^{2}$ & Estimate & SE \\
\hline Database 1: MP supply & & \\
$\beta_{\text {1pooled }}$ & 1.061 & 0.080 \\
$\beta_{2 \text { pooled }}$ & 6.979 & 2.091 \\
$\beta_{3 \text { pooled }}$ & 0.619 & 0.121 \\
Database 1: MP supply available for milk & & \\
$\beta_{\text {1pooled }}$ & 1.050 & 0.091 \\
$\beta_{2 \text { pooled }}$ & 3.988 & 0.963 \\
$\beta_{3 \text { pooled }}$ & 0.581 & 0.135 \\
Database 2: MP supply & & \\
$\beta_{1 \text { pooled }}$ & 1.744 & 0.296 \\
$\beta_{2 \text { pooled }}$ & 4.096 & 0.463 \\
$\beta_{3 \text { pooled }}$ & 1.403 & 0.288 \\
Database 2: MP supply available for milk & & \\
$\beta_{1 \text { pooled }}$ & 1.546 & 0.252 \\
$\beta_{2 \text { pooled }}$ & 2.320 & 0.333 \\
$\beta_{3 \text { pooled }}$ & 1.274 & 0.327 \\
\hline
\end{tabular}

${ }^{1}$ Parameters represent pooled estimates across publications obtained with generalized nonlinear least squares.

${ }^{2}$ Logistic model. The MP supply refers to either the MP supply according to Lapierre et al. (2014) for database 1 or White et al. (2017a,b) for database 2. The MP supply available for milk is the MP supply minus the MP required for maintenance. Database 1 is from Martineau et al. (2017), and database 2 is from White et al. (2016). $\beta_{1 \text { pooled, }}$ $\beta_{2 \text { pooled }}$, and $\beta_{3 \text { pooled }}$ are the parameters of the logistic curve associated with the horizontal asymptote, amplitude, and steepness of the curve, respectively.

to the MP supply in both databases when using either the total MP supply or MP supply available for milk production. The residuals versus predicted values' plots
(Figure 3) also suggest reasonable ability of the fitted models in describing the data.

When models were fitted with total MP supply as the independent variable, the cumulative efficiency will be lower because the total MP supports protein requirement for both milk protein secretion and maintenance, and therefore, the estimated requirement covers both maintenance and milk production. Conversely, when using MP supply available for milk production (i.e., total MP supply minus MP supply required for maintenance) as the independent variable, both the efficiency and the requirement refer exclusively to lactation. Both approaches have advantages and disadvantages. For instance, by using the total MP supply as the independent variable, the MP requirements for maintenance and lactation cannot be separated and the implicit assumption is that the MP requirement for maintenance is contained in the inefficiency of the milk protein yield. In this approach, the efficiency, and consequently the inefficiency, vary with MP supply (Figure 4). On the other hand, when using MP available for milk production as the independent variable, the MP requirement for maintenance is first subtracted from the MP supply, and other factors affecting maintenance requirements are directly used to calculate MP supply (e.g., BW). The disadvantage of this approach is that, first, it assumes a fixed efficiency of utilization of MP supply to cover maintenance requirements, and second, errors associated with the prediction of scurf protein, urinary

Table 3. Parameter posterior means, SD, 95\% credible intervals (CrI), and root mean squared prediction error (RMSPE) for the models describing the relationship between milk protein yield and MP supply (all expressed in $\mathrm{kg} / \mathrm{d})^{1}$

\begin{tabular}{lcccc}
\hline Model $^{2}$ & $\begin{array}{c}\text { Posterior } \\
\text { mean }\end{array}$ & $\begin{array}{c}\text { Posterior } \\
\text { SD }\end{array}$ & $\begin{array}{c}95 \% \\
\text { CrI }\end{array}$ & $\begin{array}{c}\mathrm{RMSPE}^{3} \\
\text { (\% of mean) }\end{array}$ \\
\hline $\begin{array}{l}\text { Database 1: Total MP supply } \\
\beta_{1}\end{array}$ & 1.166 & 0.023 & $(1.140,1.225)$ & 19.1 \\
$\beta_{2}$ & 4.875 & 0.697 & $(3.718,6.443)$ & \\
$\beta_{3}$ & 0.770 & 0.034 & $(0.698,0.836)$ & 20.1 \\
$\begin{array}{l}\text { Database 1: MP supply available for milk } \\
\beta_{1}\end{array}$ & 1.171 & 0.028 & $(1.141,1.244)$ & \\
$\beta_{2}$ & 2.990 & 0.406 & $(2.282,3.851)$ & \\
$\beta_{3}$ & 0.763 & 0.043 & $(0.678,0.851)$ & \\
Database 2: Total MP supply & & & & \\
$\beta_{1}$ & 1.553 & 0.065 & $(1.491,1.737)$ & \\
$\beta_{2}$ & 3.986 & 0.368 & $(3.271,4.687)$ & \\
$\beta_{3}$ & 1.199 & 0.110 & $(1.010,1.447)$ & \\
$\beta_{1}$ & & & & \\
$\beta_{2}$ & 1.541 & 0.053 & $(1.491,1.683)$ & \\
$\beta_{3}$ & 2.279 & 0.174 & $(1.966,2.644)$ & \\
\hline
\end{tabular}

${ }^{1}$ Parameters represent population estimates of hierarchical models using Bayesian inference.

${ }^{2}$ Logistic model. The MP supply refers to either the MP supply according to Lapierre et al. (2014) for database 1 or White et al. (2017a,b) for database 2. The MP supply available for milk is the MP supply minus the MP required for maintenance. Database 1 is from Martineau et al. (2017), and database 2 is from White et al. (2016). $\beta_{1 \text { pooled }}, \beta_{2 \text { pooled }}$, and $\beta_{3 \text { pooled }}$ are the mean population parameters associated with the horizontal asymptote, amplitude, and steepness of the logistic curve, respectively.

${ }^{3}$ Computed with a 5 -fold cross-validation. 
endogenous protein, metabolic fecal protein, and endogenous protein reaching the duodenum are introduced in the analysis. If any of the equations to predict these values do not perform well, or if the efficiencies of MP utilization for these maintenance components are incorrect, errors are directly introduced in the calculation of MP supply available for milk production. Likewise, if these calculations of maintenance outputs are added to the dependent variable in an attempt to re-construct the total protein output (defined by protein in scurf + endogenous urinary + metabolic fecal protein + milk true protein yield), errors can be added to the total protein output.

Models fitted with database 2 have a larger asymptote than models fitted with database 1 . For the models fitted with MP supply as the independent variable (Figure 2, panels a and c), the asymptotes were 1.17 (posterior $\mathrm{SD}=0.02)$ and $1.55($ posterior $\mathrm{SD}=0.06)$, suggesting that the milk protein yield converges to 1.17 and $1.55 \mathrm{~kg} / \mathrm{d}$ when MP supply approaches infinity. When the same models were fitted with MP supply available for milk production as the independent variable (Figure 2, panels $\mathrm{b}$ and $\mathrm{d}$ ), the asymptotes were basically the same as for MP supply: 1.17 (posterior SD $=0.03$ ) and 1.54 (posterior $\mathrm{SD}=0.03$ ) for database 1 and 2 , respectively. The inflection point of the logistic curve ranged from 0.58 to $0.78 \mathrm{~kg} / \mathrm{d}$ milk protein yield in the 2 databases. The MP supply at the inflection point for database 1 was $1.22 \mathrm{~kg} / \mathrm{d}$ when using total MP supply and $0.83 \mathrm{~kg} / \mathrm{d}$ when using MP supply available for milk production. Similarly, for database 2, the MP supplies at the inflection point were 1.66 and 1.05 $\mathrm{kg} / \mathrm{d}$ when using the independent variable as total MP supply and MP supply available for milk production, respectively. The second database has an inflection point that is shifted to the right relative to the first
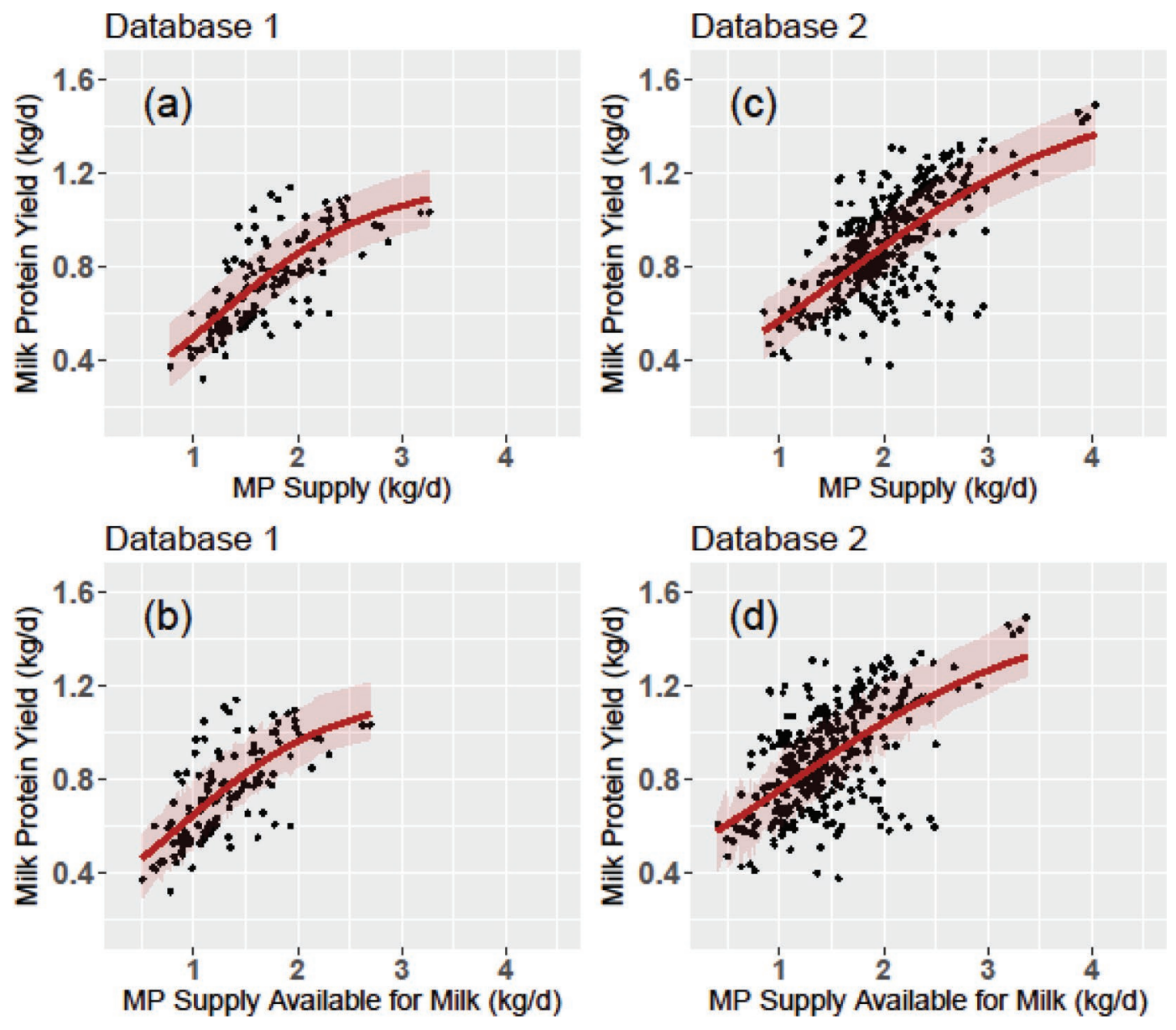

Figure 2. Milk protein yield versus total MP supply or MP supply available for milk production (MP supply minus MP required for maintenance). Points are the treatment means, the shaded area is the $95 \%$ credible interval of the posterior predictive distributions, and the curves collect the predictions using population mean parameters. Panels (a) and (b) present the data and fit based on the first database comprising treatment means of casein infusion studies. Panels (c) and (d) present data and fit based on the larger data set comprising a larger variety of studies. Database 1 is from Martineau et al. (2017), and database 2 is from White et al. (2016). Color version available online. 
database, suggesting that cows in this database achieve maximum marginal efficiency at greater levels of MP supply. A nonlinear relationship between milk protein yield and MP supply is more evident in database 1 (Figure 2). As previously discussed, database 2 has a much broader set of experimental conditions.

The objective of fitting the model with database 2 was to examine the appropriateness of the approach in a less controlled setting and identify the need for future model development possibly including the incorporation of additional factors such as diet composition, AA supplies, and BW. By design, studies with casein infusion in database 1 are likely to have improved both AA profile and supply, whereas in database 2 studies comprise a diverse mix of AA profiles in RUP with treatments that were not always designed to systematically alter dietary MP supply directly within a study.
It can be argued that not all studies in database 2 were designed to systematically vary MP supply as in database 1 and additional dietary treatments (not related to protein supply) will affect the nonlinear relationship relatively to the one from the casein database. However, the casein infusion data (database 1) might not represent the relationship between dependent and independent variables when other profiles of AA constitute MP. For instance, Choung and Chamberlain (1992) showed that even when AA are supplemented to equivalently deliver AA relative to casein at the small intestine, milk yield was often greater with casein supplementation, although similar responses between AA and casein infusions have also been reported (Galindo et al., 2011). The authors provided 4 mechanisms for these differences such as digestibility and absorbability of individual AA, different rates of absorption, en-
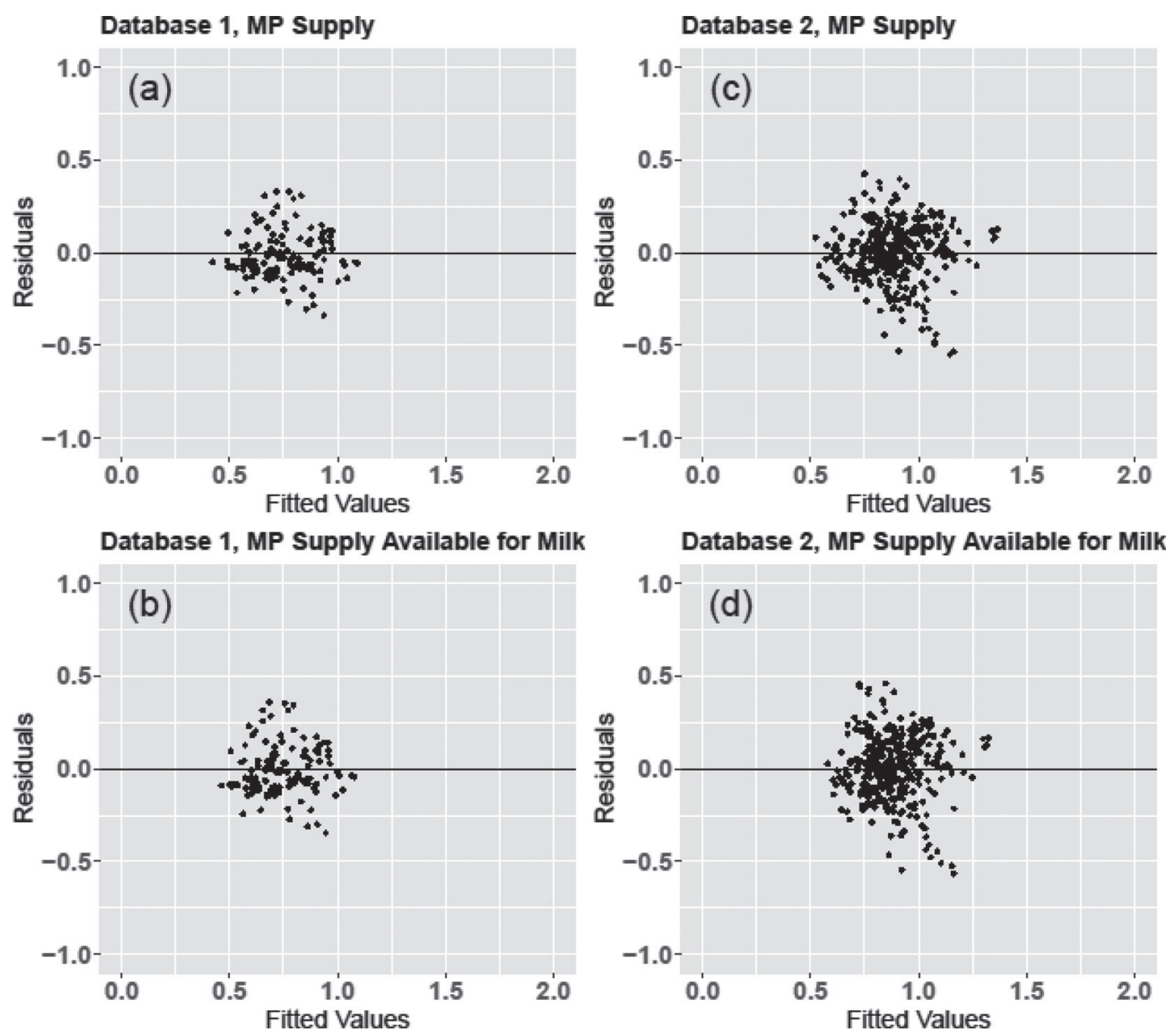

Figure 3. Residuals versus predicted milk protein yields using population mean parameters of the Bayesian models fitted with either MP supply or MP supply available for lactation in the 2 databases. Panels (a) and (b) present the data and fit based on the first database comprising treatment means of casein infusion studies. Panels (c) and (d) present data and fit based on the larger data set comprising a larger variety of studies. Database 1 is from Martineau et al. (2017), and database 2 is from White et al. (2016). Residuals and predictions were computed with models from Table 3 that only contain mean population parameters (i.e., study random deviation from the parameters of the logistic curve were set to zero). 
docrine responses, and nutrient utilization, and that peptides produced during protein digestion are biologically active (particularly for casein), affecting the rate and extent of the digestion and absorption of nutrients (Choung and Chamberlain, 1992). In this context, examining the adequacy of the proposed models in both databases provided complementary information. The fit from database 1 (Figure 2, panels a and c) suggests a more sigmoidal pattern. On the other hand, models fitted with database 2 (Figure 1, panes b and d) suggest a larger inflection point and asymptote. From a modeling perspective, it is important to note that although parameter estimates in both databases are not the same, the milk protein predictions, efficiencies, and requirements follow remarkably consistent patterns. The larger variation in database 2 suggests that future development of the approach with adaption to specific feeding conditions and cow characteristics might be needed for using the model in practice. For example, dietary nutrient composition, including energy content, AA profile of MP, BW, and an assessment of the cow's potential (Daniel et al., 2017) can be used to adapt the system to specific conditions. We investigated a potential effect of BW changes on the observed cumulative efficiency with a subset of the data that reported BW changes. The reasoning was that protein mobilization in early lactation or deposition later in lactation could affect the efficiency of yielding milk protein. No statistically significant relationship was identified. Although the contribution of body protein deposition or mobilization may be important on specific feeding and management conditions, our database is mostly composed of short-term studies with abundance of Latin squares and switchback designs which do not allow a proper characterization of protein deposition or mobilization effects on milk protein yield.

\section{Database 1}

\section{(a)}

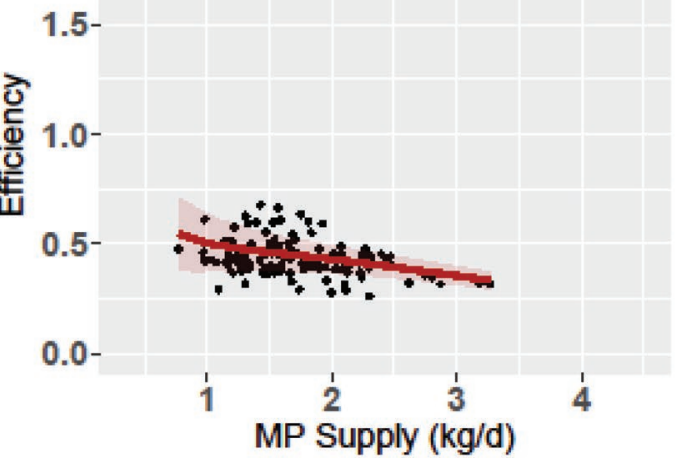

\section{Database 1}

(b)

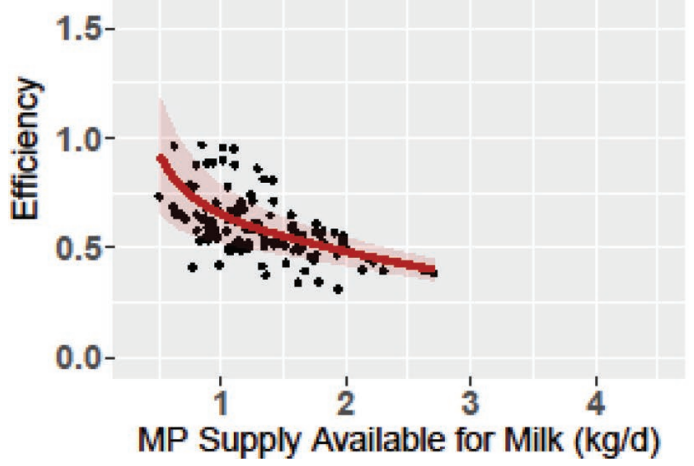

Database 2

(c)

$1.5-$

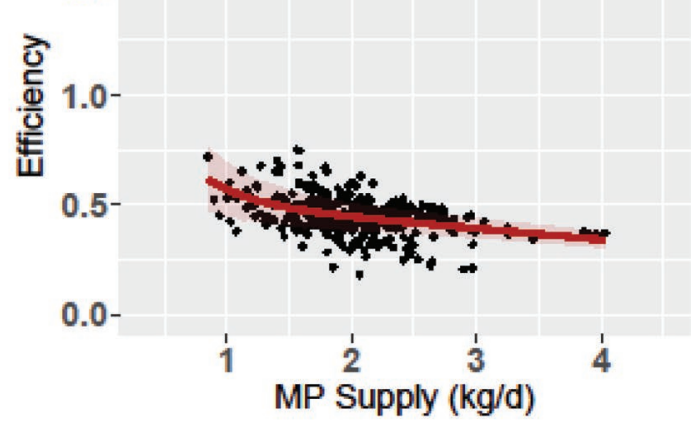

Database 2

(d)

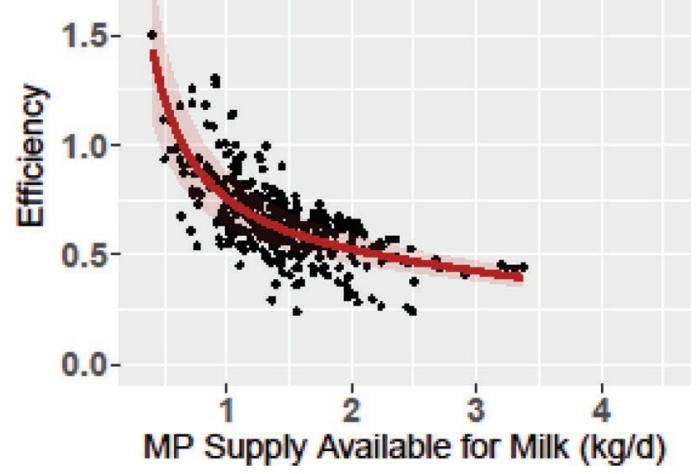

Figure 4. Cumulative efficiencies versus MP supply. Points are the treatment means (milk protein yield/MP supply), the shaded area $95 \%$ is the credible interval of posterior predictive distributions, and the curves collect the predicted efficiencies using the population mean parameters for each model (i.e., predicted milk protein yield/MP supply). Panels (a) and (b) present the data and fit based on the first database comprising treatment means of casein infusion studies. Panels (c) and (d) present data and fit based on the larger data set comprising a larger variety of studies. Database 1 is from Martineau et al. (2017), and database 2 is from White et al. (2016). Color version available online. 
The logistic model has been extensively used to represent animal responses to nutrient supply. For example, Kebreab et al. (2003) used the logistic function to represent the milk energy output response to ME supply by lactating dairy cows. Doepel et al. (2004) used the logistic model to represent the response of milk protein synthesis to AA supplies in lactating dairy cows. The logistic model is asymptotic, that is, it converges to an asymptotic milk protein yield as the MP supply approaches infinity rather than reaching a plateau such as linear and quadratic piecewise plateau models. St-Pierre and Thraen (1999) discussed desired features of functions describing responses to nutrient supply by animals. In particular, these authors suggested that biological principles imply that only individual animals of identical genetics, physiological state, and environment have a piecewise function with a plateau. Functions to represent responses to nutrient supply on a population basis have to be smooth and converge to an asymptote (Curnow, 1973; St-Pierre and Thraen, 1999) such as the one used in the present study. Therefore, the logistic models fitted in this study might be used as the basis of a framework to predict milk protein yield responses to MP supply and determine the MP requirements.

\section{Predicted Cumulative Efficiencies}

The observed cumulative efficiencies can be computed as the ratio of the milk protein yield and the MP supply. The predicted efficiencies, using the mean population parameters in each model, are therefore given by $f(\mathrm{MP}, \hat{\boldsymbol{\beta}}) / \mathrm{MP}$. The observed efficiencies, as well as the predicted efficiencies by each model, are plotted versus MP supply in Figure 4. From this figure, it is clear that (1) the observed efficiencies decrease as a function MP supply, (2) the fitted logistic models predict milk protein yield with a cumulative variable efficiency of MP utilization, and (3) the predicted cumulative efficiencies by all models are in good agreement with the observed efficiencies.

The efficiency of total MP supply utilization is, by definition, smaller than the efficiency of using MP supply only available for milk production. The latter is computed with a smaller denominator and consequently has a larger value (Figure 4, panels b and d). When using total MP supply, the observed efficiencies ranged from 0.68 to 0.26 in database 1 and 0.75 to 0.18 in database 2. If MP supply available for milk production is used as the independent variable, the observed efficiencies ranged from 0.96 to 0.31 in database 1 and from above 1 to 0.24 in database 2. The predicted efficiencies in all models are in good agreement with the data (Figure 4), suggesting a nonlinear decrease of the cumulative efficiency with increasing in MP supply. The calculated efficiencies at low MP supplies available for milk are close to (and even larger than) 1. Biologically, this might be an indication that animals are utilizing $\mathrm{N}$ sources other than MP supply, such as tissue mobilization and urea recycling. Alternatively, this might suggest that the correction for maintenance might have been excessive or that predictions in the logistic curve are approaching the part of the curve at which the cumulative efficiency increases excessively fast (i.e., at milk protein yields neighboring the intercept).

The first publication reporting, from many studies, that MP is used with variable efficiency was from Subnel et al. (1994). Similarly, Hanigan et al. (1998) suggested lower efficiencies at greater MP supplies. Since then, the variable efficiency concept was incorporated into feeding systems of various countries (e.g., VanDuinkerken et al., 2011; Volden, 2011; Sauvant et al., 2015). The model proposed in the present study differs from most of these models from the literature although it share similarities with the approach from Sauvant et al. (2015). In particular, it was constructed with the relationship between milk protein yield and MP supply, whereas many models from the literature use a ratio as the dependent variable (i.e., protein yield/MP supply or the efficiency) for which the denominator is also often used as an independent variable (or at least to construct the independent variable such as MP supply/ $\mathrm{NE}_{\mathrm{L}}$ supply or MP supply/DMI). Many recent studies examined the variable efficiency of MP utilization, for example, Arriola Apelo et al. (2014) suggested that the efficiency of MP utilization decreases with MP supply in a curvilinear fashion. Likewise, Metcalf et al. (2008) suggested that the amount of protein captured in milk with the efficiencies below and above MP requirement levels determine a set of efficiencies described by a curvilinear function (Metcalf et al., 2008). In addition, Sauvant et al. (2015) introduced the concept of a variable efficiency of protein utilization for both lactation and maintenance, as also discussed by Lapierre et al. (2007), which is different than most systems that only suggest a variable efficiency of MP for lactation.

Finally, it is important to note that other studies suggest that both MP and energy supplies affect the efficiency (e.g., Subnel et al., 1994; van Duinkerken et al., 2011; Volden, 2011; Daniel et al., 2016) as well as the ratio MP/DMI (Sauvant et al., 2015). However, none of the models fitted in our study use $\mathrm{NE}_{\mathrm{L}}$ supply as an additional independent variable. The reason for not including $\mathrm{NE}_{\mathrm{L}}$ was the large correlation between $\mathrm{MP}$ and $\mathrm{NE}_{\mathrm{L}}$ supplies $(\mathrm{r}=0.85$ for database 1 and $\mathrm{r}$ $=0.79$ for database 2 ), which could potentially lead to multi-collinearity issues. As variation in MP in each study in database 1 was mostly from casein infusion 
(as described in Martineau et al., 2017), the variation in $\mathrm{NE}_{\mathrm{L}}$ supply was basically the MP variation times a fixed factor, which made changes in supplies, within study, relatively similar between $\mathrm{MP}$ and $\mathrm{NE}_{\mathrm{L}}$. Daniel et al. (2016) adjusted both $\mathrm{NE}_{\mathrm{L}}$ and $\mathrm{MP}$ supplies to reduce the collinearity between both variables, with MP supply adjusted relative to the supply needed for an efficiency of 0.67. The authors, however, found that the interaction of $\mathrm{MP}$ and $\mathrm{NE}_{\mathrm{L}}$ supplies was not statistically different from zero (Daniel et al., 2016) in a second-order polynomial model for milk protein yield. As a general conclusion, the authors suggest that although the effect of MP and $\mathrm{NE}_{\mathrm{L}}$ supplies on milk protein yield were additive, $\mathrm{MP}$ and $\mathrm{NE}_{\mathrm{L}}$ supplies are inherently correlated because these 2 supplies are never independent. Likewise, Hanigan et al. (1998) also described interactive effects of protein and energy supplies. In this context, the model proposed in this study does not directly account for the individual effects of MP and $\mathrm{NE}_{\mathrm{L}}$ supplies on the prediction of milk protein yield, efficiencies, and requirements, but model parameters are not strictly independent of the effect of $\mathrm{NE}_{\mathrm{L}}$ supply because of the inherent correlation between protein and energy supplies. Extensions of the proposed model are possible, for example, with the potential inclusion of energy as a covariate for the parameters of a nonlinear model (Pinheiro and Bates, 2000).

\section{MP Requirements}

The general strategy for determining the MP requirement was to determine the MP solution, that is, to invert the milk protein yield model. The MP requirement, for a given milk protein yield, was defined as the MP supply needed to predict that given output in the fitted curve (the MP solution). It is important to note that this strategy is one approach to compute the required MP that assumes that the protein yield is the main driver of the required MP. In fact, this approach is similar to the one proposed by the Dutch system that computes the lactation requirement with a quadratic function of the protein yield (van Duinkerken et al., 2011). The model used by the Dutch system was first proposed by Subnel et al. (1994) describing the quadratic function as a strategy to represent requirements, per unit milk protein, that increase when milk protein yield increases. The reasoning for our function also representing requirements that increase with protein yield is the nonlinear relationship between milk protein yield and MP supply. In particular, after the inflection point, the logistic curve determines diminishing returns to the MP supply. The rate of protein yield secretion decreases when MP supply is increased and consequently more MP is needed to secrete 1 unit of protein at greater supplies. The fact that the equation to compute the MP requirement depends only on the protein yield is convenient as most diets are in practice formulated or optimized for a given (or target) level of milk production. However, it must be pointed out that the biological relationship of the efficiency is with the MP supply and not strictly with the protein yield itself because the MP supply is the variable affecting the efficiency of protein utilization (Figure 4).

The MP supply at the inflection point and the MP supply at which the second derivative of the logistic curve attained its minimum were used to adjust the requirement before or after these critical supplies. Close to the model intercept, the MP requirement gets excessively close to zero. At the intercept, the requirement of MP by inversion is undefined and would equal, biologically, to zero. In contrast, the MP requirement at the asymptote is undefined and would equal infinity. The requirements before the inflection point and after the critical point were then calculated in our approach as the milk protein yield divided by the predicted efficiency at these points. Changing from the inverse function to the efficiency approach at the inflection and critical MP supplies keeps the requirement function connected but prevents the calculation of extreme requirements at both ends of the function. The MP requirements in the 2 databases using both total MP supply and MP supply available only for milk production are in Figure 5 . For comparison, the requirement computed with the NRC (2001) for either lactation plus maintenance or solely for lactation is also presented in Figure 5. A general pattern can be observed in the 4 panels of Figure 5 . Requirements were often slightly lower than the ones determined with the NRC (2001) system at lower levels of milk protein yield and greater than requirements from the current system at greater levels of protein yield, most likely because of the constant 0.67 efficiency used by the NRC (2001). Examination of panels (b) and (d) of Figure 4 suggests that the efficiency is substantially greater than 0.67 at low MP supplies and substantially lower than 0.67 at greater supplies. Somewhere between 0.9 and $1.2 \mathrm{~kg} / \mathrm{d}$ of MP supply, the efficiency of using MP for lactation approximately equals the 0.67 used in the NRC (2001). These results are in agreement with Lapierre et al. (2014), who suggested that MP allowable milk is often overestimated at high MP supplies and underestimated at low MP supplies in both NRC (2001) and Cornell Net Carbohydrate and Protein System (Fox et al., 2004) models. Therefore, if the nonlinear relationship between protein yield and MP supply is proper, calculating MP requirements using the constant 0.67 fixed efficiency will most 
likely overestimate MP requirements at low yields and underestimate requirements at high yields.

The model used in this study is asymptotic, with direct implication that the model cannot predict a milk protein yield larger than the asymptote. From a data analysis perspective, this presents no further challenges because the asymptote in all fitted models is larger than the milk protein output in both databases. These asymptotes suggest that cows in our database have not reached their potential milk protein yield, for that given environment. From the perspective of predicting milk protein yield, model users should be aware that extrapolation outside the range of the data for which the models were fit is dangerous (Kutner et al., 2004; Conn et al., 2015). We therefore warn model users that the models should be used with caution for predict- ing milk protein yields with MP supplies greater than 3.27 and $4.03 \mathrm{~kg} / \mathrm{d}$ because these are the maximum MP supplies in databases 1 and 2, respectively. Similarly, the determination of MP requirements for milk protein yields above 1.14 and $1.49 \mathrm{~kg} / \mathrm{d}$ must be done with caution as these are the maximum protein yields in database 1 and 2. These limitations are not because of the chosen models or statistical techniques but due to the ranges on the data. Moreover, it is important to note that the models fitted in this study, as well as the predicted requirements and efficiencies, rely heavily on the data used for model fitting, as the majority of statistical techniques.

The main objective of this study was to develop a system that directly represents the nonlinear relationship between milk protein yield and MP supply by allowing
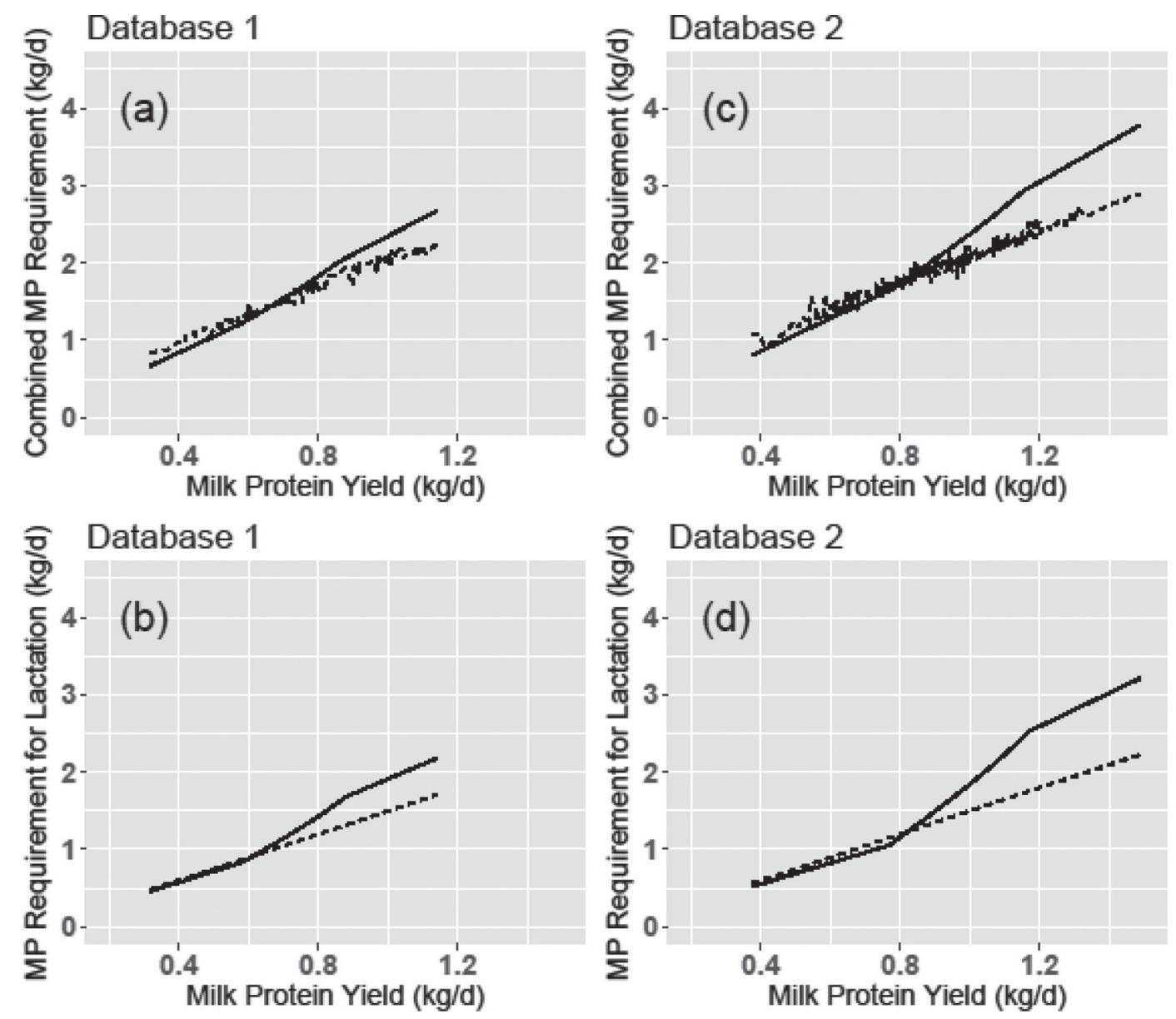

Figure 5. Metabolizable protein requirement versus milk protein yield. The first row of panels presents the total MP requirement (i.e., requirement for maintenance plus lactation), whereas the second row of panels presents the MP requirement for lactation. The dashed line is the requirement calculated with the NRC (2001) model and the solid line the MP requirement computed with the new approach. Panels (a) and (b) present the requirements based on the first database comprising treatment means of casein infusion studies. Panels (c) and (d) present the requirements based on the larger data set comprising a larger variety of studies. It is important to note that for both databases, the MP supply needed for endogenous sources reaching the duodenum was not included in both requirement and supply. Therefore, the NRC (2001) requirement for maintenance was also computed without this protein fraction. 
between-study variability to be introduced nonlinearly. Biologically, the main objective was to develop a system to determine MP requirements that directly relies on the nonlinear relationship between milk protein yield and MP supply. The proposed requirement function uses the inverse of the logistic model. It is important to point out, however, that factors other than MP supply affect milk protein yield, such as energy supply, AA profile of MP, and animal characteristics such as BW changes and its environment. Future work will be needed to adapt the proposed modeling framework developed to include these specific conditions. For example, we previously discussed that MP supply is never independent of $\mathrm{NE}_{\mathrm{L}}$ supply, although both have been identified as contributors to the efficiency. Moreover, the proposed model does not take into account the potential of different cows within a given environment. In a recent publication, Daniel et al. (2017) developed an approach to quantify the cow potential and to estimate subsequent responses to varying nutrient supplies, including current and past environmental effects on the production potential. Approaches such as this one will need to be included in the proposed model to better predict the milk protein yield in response to a diet under specific conditions. The individual AA supply, as well as the $\mathrm{NE}_{\mathrm{L}}$ supply (as discussed above) are known to alter the efficiency of MP or AA utilization (Hanigan et al., 1998; Doepel et al., 2004) and therefore MP requirement. The idea of adjusting for these dietary and animal factors seems a promising way to expand the proposed modeling approach and create a system that will be able to respond generally to different feeding situations and different cows. One approach that might be fruitful is the use of covariates to model the parameters of nonlinear models, as described by Pinheiro and Bates (2000) with the use of covariates in nonlinear mixed models.

\section{Using the Models in Practice}

All the information necessary to compute the MP solutions using the proposed system is given in Table 3. That is, all the steps necessary for the construction of the requirement function rely exclusively on the use of parameter estimates from Table 3. We proposed to modify the inverse function at the inflection point and critical MP supply but other alternatives might also be valid. For example, model users can use different MP supplies to switch the requirement function from the inverse to the efficiency approach. Instead, model users can predict average cumulative efficiencies at given ranges and calculate the requirement by dividing milk protein yield by the average efficiency in a specific range of the curve, completely eliminating the need of an inverse of the logistic model. Finally, model users can further modify these models with dietary and animal factors and make the MP requirement a function of these variables.

To demonstrate the use of the models in practice, 2 examples are provided with the detailed determination of MP requirements for 2 records in our database. In the first example, the total MP requirement is calculated for a cow that outputs $0.438 \mathrm{~kg} / \mathrm{d}$ of milk protein with a $530 \mathrm{~kg}$ of BW and a DMI of $11.3 \mathrm{~kg} / \mathrm{d}$. Using parameter estimates for database 2 with total MP supply as the independent variable (Table 3 ), the inflection point is $y_{p}=\beta_{1} / 2=0.776 \mathrm{~kg} / \mathrm{d}$ of protein yield and the critical MP supply is

$$
\begin{aligned}
x_{u} & =1.199 \times \log (\sqrt{3 \times 3.986}+2 \times 3.986) \\
& =2.921 \mathrm{~kg} / \mathrm{d} \text { of MP },
\end{aligned}
$$

where $x_{u}=2.921$ is given in kilograms per day of MP and represents the MP supply from which the marginal efficiency decreases rapidly. The corresponding predicted milk protein yield at $x_{u}$ is $y_{u}=1.151 \mathrm{~kg} / \mathrm{d}$. The MP supply at the inflection point is given by $x_{p}$ $=-\beta_{3} \log \left(1 / \beta_{2}\right)=1.657 \mathrm{~kg} / \mathrm{d}$ of MP. The efficiencies at these 2 points are $\delta_{p}=0.468$ and $\delta_{u}=0.394$. In this study, $x_{u}$ and $x_{p}$ are used to limit changes on the efficiency, and consequently on the requirement, in the extreme parts of the curve. The requirement function comprises 3 parts that are curtailed in the extremes by efficiencies at $x_{u}$ and $x_{p}$, as previously discussed. For this example, it is given by

$$
\begin{gathered}
R(0.438)=I_{\{0.438 \leq 0.776\}} \frac{0.438}{0.468}+I_{\{0.776<0.438<1.151\}} \\
\left\{-1.199 \times \log \left[\frac{1}{3.986}\left(\frac{1.553}{0.438}-1\right)\right]\right\}+I_{\{0.438 \geq 1.151\}} \frac{0.438}{0.394}
\end{gathered}
$$

The function in this case determines the MP needed (in $\mathrm{kg} / \mathrm{d}$ ) for the total MP requirement (maintenance plus lactation). The first step in the calculation of the MP solution is the identification of which of the 3 indicator functions returns a nonzero value (i.e., which indicator function has the condition within braces satisfied). In this example, milk protein yield is $0.438 \mathrm{~kg} / \mathrm{d}$, and the first indicator function in the right-hand side of the equation is the one returning a nonzero value. The total requirement (i.e., maintenance plus lactation) is therefore given by $0.438 / 0.468=0.900 \mathrm{~kg} / \mathrm{d}$ of MP. The requirement determined by the NRC (2001) for maintenance plus lactation for this cow is approximately 1.08 $\mathrm{kg} / \mathrm{d}$ of MP. 
In the second example, a record with a greater protein output was selected. This example is for a cow that outputs $1 \mathrm{~kg} / \mathrm{d}$ of protein in milk. The model fitted with database 2 and MP supply available only for milk production will be used to calculate the MP requirement for lactation for this cow. It is important to note that in this example, the MP supply needed for maintenance has been subtracted from the total MP supply and the solution computed will be referent only to the MP required for lactation. Using parameter estimates from Table 3 , the inflection point is $y_{p}=\beta_{1} / 2=0.770$ $\mathrm{kg} / \mathrm{d}$ of protein yield, the MP supply at the inflection point is $x_{p}=-\beta_{3} \log \left(1 / \beta_{2}\right)=1.053 \mathrm{~kg} / \mathrm{d}$ of $\mathrm{MP}$ and the critical MP supply:

$$
\begin{aligned}
x_{u} & =1.279 \times \log (\sqrt{3 \times 2.279}+2 \times 2.279) \\
& =2.520 \mathrm{~kg} / \mathrm{d} \text { of MP },
\end{aligned}
$$

with corresponding $y_{u}=1.169 \mathrm{~kg} / \mathrm{d}$ of milk protein. The efficiencies at the inflection point and the critical MP supply are $\delta_{p}=0.731$ and $\delta_{u}=0.464$. The requirement function is therefore

$$
\begin{gathered}
R(1.00)=I_{\{1 \leq 0.770\}} \frac{1}{0.731}+I_{\{0.770<1<1.169\}} \\
\left\{-1.279 \times \log \left[\frac{1}{2.279}\left(\frac{1.541}{1}-1\right)\right]\right\}+I_{\{1 \geq 1.169\}} \frac{1}{0.464} .
\end{gathered}
$$

Again, the first step in the determination of the MP solution is to identify which of the indicator functions return a nonzero value. The second (or middle) term in the equation right-hand side is the one that has the condition of the indicator function satisfied (i.e., 0.770 $<1<1.169)$. The MP requirement for lactation is therefore given by the inverse function, equaling 1.839 $\mathrm{kg} / \mathrm{d}$ of MP for lactation. The NRC (2001) requirement of MP for lactation for this cow would be $1 / 0.67=$ $1.492 \mathrm{~kg} / \mathrm{d}$ of MP for lactation. In this second example, the requirement refers only to the MP for lactation. The amount of MP required to cover maintenance costs would, therefore, have to be calculated with another system and added to this value for the determination of the total MP requirement. In our example, we have used the maintenance efficiencies and requirements to compute the MP supply available for lactation according to the NRC (2001).

The requirements in these 2 examples demonstrate the overall trend of our models in estimating MP requirements. All models from Table 3 determine MP requirements that are slightly lower than NRC (2001) requirements at lower levels of milk yield and MP requirements that are greater than the NRC (2001) model for high yields (Figure 5). The point at which the requirements from our models become larger than the NRC (2001) requirements and the magnitude of the difference depend on the parameter estimates of the logistic curve that determines the inverse function, the inflection point, critical MP supply, and the associated efficiencies. As previously discussed, it is important to point out that, after the inflection point, the rate of protein yield secretion decreases when MP supply is increased in the logistic function, and consequently, more MP is needed to secrete 1 unit of protein at greater MP supplies. However, the biological relationship of the efficiency is with the MP supply and not strictly with the protein yield itself because the MP supply is the variable affecting the efficiency of protein utilization (Figure 4). Although it is not the main objective of this manuscript to compare the proposed system with the NRC (2001) model, many studies from the literature point out the issue with the constant efficiency assumed by the system and the consequent under and over estimation of efficiencies, MP-allowable milk and requirements (e.g., Lapierre et al., 2007; Arriola Apelo et al., 2014). Results from the model proposed in this study seem to be in alignment with the concept of a variable efficiency and requirement as adopted by feeding systems worldwide (e.g., van Duinkerken et al., 2011; Volden, 2011; Sauvant et al., 2015). The use of the system in practice might still be dependent on its adaptation to specific feeding conditions.

\section{CONCLUSIONS}

The models fitted in this study predict the milk protein yield response to MP supply with nonlinear returns in 2 databases, the first based on casein-infusion studies and the second on dietary treatments. All models provided a reasonable fit to the data as suggested by the RMSPE ranging from 18 to $20 \%$ of the average milk protein yield. The cumulative efficiencies decreased with MP supply in a nonlinear fashion and were considerably larger than the constant 0.67 efficiency suggested by the NRC (2001) at lower MP supplies and considerably lower at greater supplies. Somewhere between 0.9 and $1.2 \mathrm{~kg} / \mathrm{d}$ of MP supply, the efficiency of utilizing MP for lactation was similar to the 0.67 efficiency suggested by the NRC (2001) in both databases. The requirement of MP was calculated as the MP solution by inverting the protein output model and identifying, for a given milk protein yield, the MP needed to predict that yield in the fitted curve. To prevent the determination of excessively low or high MP requirements, before the inflection point and after the point of minima of the logistic curve second derivative, requirements were computed by the protein yield divided by the predicted 
efficiency. For both databases, MP requirements either for maintenance plus lactation or exclusively for lactation, were slightly smaller than NRC (2001) at low yields but greater than requirements from the current system at high yields. As proposed, the methodology developed in this study will be further developed to include specific dietary or cow characteristics to improve both the predictions of milk protein yield and the generalization of the computed MP solutions as the MP requirements.

\section{ACKNOWLEDGMENTS}

Research was partially supported by the University of California, Davis Sesnon Endowed Chair program, the USDA National Institute of Food and Agriculture Multistate Research Project NC-2040 (University of California-Davis), the Dairy Farmers of Canada (Ottawa, Canada), and Agriculture and Agri-Food Canada. The authors thank Yairanex Roman-Garcia (Columbus, OH) for her assistance with the databases.

\section{REFERENCES}

Arriola Apelo, S. I., J. R. Knapp, and M. D. Hanigan. 2014. Invited review: Current representation and future trends of predicting amino acid utilization in the lactating dairy cow. J. Dairy Sci. 97:4000-4017.

Carpenter, B., A. Gelman, M. Hoffman, D. Lee, B. Goodrich, M. Betancourt, M. A. Brubaker, J. Guo, P. Li, and A. Riddell. 2016. Stan: A probabilistic programming language. J. Stat. Softw. 76:132. https://doi.org/10.18637/jss.v076.i01.

Choung, J.-J., and D. G. Chamberlain. 1992. Protein nutrition of dairy cows receiving grass silage diets. The effects of post-ruminal supplements of proteins and amino acids. J. Sci. Food Agric. 60:25-30.

Conn, P. B., D. S. Johnson, and P. L. Boven. 2015. On extrapolating past the range of observed data when making statistical predictions in ecology. PLoS One 10:e0141416. https://doi.org/10.1371/ journal.pone.0141416.

Curnow, R. N. 1973. A smooth population response curve based on an abrupt threshold and plateau model for individuals. Biometrics 29:1-10.

Daniel, J. B., N. C. Friggens, P. Chapoutot, H. Van Laar, and D. Sauvant. 2016. Milk yield and milk composition responses to change in predicted net energy and metabolizable protein: A meta-analysis. Animal 10:1975-1985.

Daniel, J. B., N. C. Friggens, H. Van Laar, C. P. Ferris, and D. Sauvant. 2017. A method to estimate cow potential and subsequent responses to energy and protein supply according to stage of lactation. J. Dairy Sci. 100:3641-3657.

Dijkstra, J., C. K. Reynolds, E. Kebreab, A. Bannink, J. L. Ellis, J. France, and A. M. van Vuuren. 2013. Challenges in ruminant nutrition: Towards minimal nitrogen losses in cattle. Pages 47-58 in Energy and Protein Metabolism and Nutrition in Sustainable Animal Production. W. J. Oltjen, E. Kebreab, and H. Lapierre, ed. Wageningen Academic Publishers, Wageningen, the Netherlands.

Doepel, L., D. Pacheco, J. J. Kennelly, M. D. Hanigan, I. F. Lopez, and H. Lapierre. 2004. Milk protein synthesis as a function of amino acid supply. J. Dairy Sci. 87:1279-1297.

Fox, D. G., L. O. Tedeschi, T. P. Tylutki, J. B. Russell, M. E. Van Amburgh, L. E. Chase, A. N. Pell, and T. R. Overton. 2004. The Cornell Net Carbohydrate and Protein System model for evaluat- ing herd nutrition and nutrient excretion. Anim. Feed Sci. Technol. 112:29-78

Galindo, C. E., D. R. Ouellet, D. Pellerin, S. Lemosquet, I. OrtiguesMarty, and H. Lapierre. 2011. Effect of amino acid or casein supply on whole body, splanchnic, and mammary glucose kinetics in lactating dairy cows. J. Dairy Sci. 94:5558-5568.

Gelman, A., and D. B. Rubin. 1992. Inference from iterative simulation using multiple sequences. Stat. Sci. 7:457-472.

Hanigan, M. D., J. P. Cant, D. C. Weakley, and J. L. Beckett. 1998. An evaluation of postabsorptive protein and amino acid metabolism in the lactating dairy cow. J. Dairy Sci. 81:3385-3401.

Huhtanen, P., and A. N. Hristov. 2009. A meta-analysis of the effects of dietary protein concentration and degradability on milk protein yield and milk $\mathrm{N}$ efficiency in dairy cows. J. Dairy Sci. 92:3222-3232.

Kebreab, E., J. France, R. E. Agnew, T. Yan, M. S. Dhanoa, J. Dijkstra, D. E. Beever, and C. K. Reynolds. 2003. Alternatives to linear analysis of energy balance data from lactating cows. J. Dairy Sci. 86:2904-2913.

Kutner, M., C. Nachtsheim, J. Neter, and W. Li. 2004. Applied Linear Statistical Models. 5th ed. McGraw Hill/Irwin, Chicago, IL.

Lapierre, H., L. Doepel, D. Pacheco, and D. R. Ouellet. 2014. Amino acid requirements and post-absorptive metabolism in cattle: Implications for ration formulation. Pages 166-178 in Proc. 25th Annual Florida Ruminant Nutrition Symposium. Department of Animal Sciences, University of Florida, Gainesville.

Lapierre, H., G. E. Lobley, D. R. Ouellet, L. Doepel, and D. Pacheco. 2007. Amino acid requirements for lactating dairy cows: Reconciling predictive models and biology. Pages 39-59 in Proc. Cornell Nutrition Conference for Feed Manufacturers. Department of Animal Science, Cornell University, NY.

Larsen, M., H. Lapierre, and N. B. Kristensen. 2014. Abomasal protein infusion in postpartum transition dairy cows: Effect on performance and mammary metabolism. J. Dairy Sci. 97:5608-5622.

Lewandowski, D., D. Kurowicka, and H. Joe. 2009. Generating random correlation matrices based on vines and extended onion method. J. Multivariate Anal. 100:1989-2001.

Martineau, R., D. R. Ouellet, E. Kebreab, and H. Lapierre. 2017. Relationships between postruminal casein infusion and milk production, and concentrations of plasma amino acids and blood urea in dairy cows: A multilevel mixed-effects meta-analysis. J. Dairy Sci. 100:8053-8071. https://doi.org/10.3168/jds.2016-11813.

McCubbin, D. R., B. J. Apelberg, S. Roe, and F. Divita. 2002. Livestock ammonia management and particulate-related health benefits. Environ. Sci. Technol. 36:1141-1146.

Metcalf, J., R. Mansbridge, J. Blake, J. Oldham, and J. Newbold. 2008. The efficiency of conversion of metabolisable protein into milk true protein over a range of metabolisable protein intakes. Animal 2:1193-1202.

NRC. 2001. Nutrient Requirements of Dairy Cattle. 7th ed. National Academy Press, Washington, DC.

Oenema, O. 2004. Governmental policies and measures regulating nitrogen and phosphorus from animal manure in European agriculture. J. Anim. Sci. 82(E-Suppl.):E196-E206.

Pinheiro, J., D. Bates, S. DebRoy, D. Sarkar, and R Core Team. 2016. nlme: Linear and Nonlinear Mixed Effects Models. R package version 3.1-128. http://CRAN.R-project.org/package=nlme.

Pinheiro, J., and D. M. Bates. 2000. Mixed effects models in S and SPLUS. Statistics and Computing. Springer, New York, NY.

Roman-Garcia, Y., R. R. White, and J. L. Firkins. 2016. Meta-analysis of postruminal microbial nitrogen flows in dairy cattle. I. Derivation of equations. J. Dairy Sci. 99:7918-7931.

Sauvant, D., G. Cantalapiedra-Hijar, L. Delaby, J. B. Daniel, P. Faverdin, and P. Nozière. 2015. Actualisation des besoins protéiques des ruminants et détermination des réponses des femelles laitières aux apports de protéines digestibles dans l'intestin (PDI). INRA Prod. Anim. 28:347-368.

St-Pierre, N. R. 2001. Integrating quantitative findings from multiple studies using mixed model methodology. J. Dairy Sci. 84:741-755. 
St-Pierre, N. R., and C. S. Thraen. 1999. Animal grouping strategies, sources of variation, and economic factors affecting nutrient balance on dairy farms. J. Dairy Sci. 77(Suppl. 2):72-83.

Stan Development Team. 2016a. Stan Modeling Language Users Guide and Reference Manual, Version 2.12.0. http://mc-stan.org.

Stan Development Team. 2016b. RStan: The R interface to Stan, Version 2.10.1. http://mc-stan.org.

Subnel, A. P. J., R. G. M. Meijer, W. M. van Straalen, and S. Tamminga. 1994. Efficiency of milk protein production in the DVE protein evaluation system. Livest. Prod. Sci. 40:215-224.

Swanson, E. W. 1977. Factors for computing requirements of protein for maintenance of cattle. J. Dairy Sci. 60:1583-1593.

Thornley, J. H. M., and J. France. 2005. Mathematical Models in Agriculture: Quantitative Methods for the Plant and Animal Sciences. 2nd ed. CAB International, Wallingford, UK.

USDA-EPA (Environmental Protection Agency). 1999. Unified national strategy for animal feeding operations. USDA-EPA, Washington, DC.

van Duinkerken, G., M. C. Blok, A. Bannink, J. W. Cone, J. Dijkstra, A. M. Van Vuuren, and S. Taaminga. 2011. Update of the Dutch protein evaluation system for ruminants: The DVE/OEB2010 system. J. Agric. Sci. 149:351-367.
Volden, H. 2011. NorFor-The Nordic feed evaluation system. EAAP Publications, No. 130. Wageningen Academic Publishers, the Netherlands.

White, R. R., Y. Roman-Garcia, and J. L. Firkins. 2016. Meta-analysis of postruminal microbial nitrogen flows in dairy cattle. II. Approaches to and implications of more mechanistic prediction. J. Dairy Sci. 99:7932-7944.

White, R. R., Y. Roman-Garcia, J. L. Firkins, M. J. VandeHaar, L. E. Armentano, W. P. Weiss, T. McGill, R. Garnett, and M. D. Hanigan. 2017a. Evaluation of the National Research Council (2001) dairy model and derivation of new prediction equations. 1. Digestibility of fiber, fat, protein, and nonfiber carbohydrate. J. Dairy Sci. 100:3591-3610. https://doi.org/10.3168/jds.2015-10800.

White, R. R., Y. Roman-Garcia, J. L. Firkins, P. Kononoff, M. J. VandeHaar, H. Tran, T. McGill, R. Garnett, and M. D. Hanigan. 2017b. Evaluation of the National Research Council (2001) dairy model and derivation of new prediction equations. 2. Rumen degradable and undegradable protein. J. Dairy Sci. 100:3611-3627. https://doi.org/10.3168/jds.2015-10801. 